\title{
Is SERVQUAL an inclusive indicator of SMEs' service quality advantage during an economic downgrade?A South African case
}

\author{
Carly Prinsloo \\ University of South Africa, South Africa
}

\section{Keywords}

Service quality, differentiation strategy, competitive advantage, small and medium enterprises, South Africa

\begin{abstract}
Confidence levels among small business owners are lower since South Africa's economy has been downgraded to technical recession. With the economic climate looking dismal, small business owners are not convinced that the South African government will spend on small business development. Where large and small businesses are competing for the same market share, there is a need for small businesses to differentiate themselves in some manner to attract and retain customers through the tough economic climate. A particularly excellent competitive advantage to pursue is high service-quality levels to satisfy customer wants and needs in such a way that customers make repeat purchases. The purpose of this paper is to establish if small businesses can utilise the same measurement models as larger businesses. The research utilised a quantitative research design whereby the data was collected by means of a five-point Likert scale survey, known as the SERVQUAL model. The results recommend that small and medium enterprises use the SERVQUAL model to measure and manage service quality and that the SERVQUAL instrument, when used to measure the perceptions of service quality aspects according to business owners in South Africa, functions largely as intended with only four of the items that are not quite interpreted as intended. At a confidence level of 95 percent or alpha at 0.05 is smaller than the p-value of expectations and perceptions at 0.101 and 0.076 respectively. Results indicate there is no evidence that the model does not fit the data and it is deemed acceptable. However, the SERVQUAL model does not measure service quality in its entirety, as there are aspects that differ between large and small businesses that are not addressed in the SERVQUAL model.
\end{abstract}

Corresponding author: Carly Prinsloo

Email addresses for corresponding author: prinsck@unisa.ac.za

First submission received: 10th May 2017

Revised submission received: 31st July 2017

Accepted: 1st September 2017

\section{Introduction}

Small business owners are concerned that cash-flow, economic conditions and funding will be the main issues resulting from South Africa's downgrade to technical recession by two global ratings agencies (Omarjee 2017; Moody's 2017). The pressure of low growth has further catalysed small business owners into finding a competitive advantage when competing for market share. A competitive advantage is essential to survive in the market place, as competition gets tougher, customers are wiser and more engaged (South African Reserve Bank 2016; Taneja, Pryor \& Hayek 2016:48). To maintain competitiveness, small and medium enterprises (SMEs) will need to find a strategy that will allow the business to stand out from other businesses. Often, having a competitive edge may be difficult when the business offers a product or service that is similar throughout that particular industry for example, insurance, restaurants or cellular service providers. Small businesses require a competitive advantage to operate successfully under stricter regulations and to obtain financial support where there is a lack of infrastructure and inadequate access to credit markets (Festus, Kasongo, Moses \& Yu 2016:581). Small businesses compete with fellow small businesses and larger businesses alike. Consider that larger businesses have the advantage of greater financial, human, technological and intellectual resources (Dessi, Ng, Floris \& Cabras 2014:669), it is necessary for a small business to find a way to differentiate itself in some way to compete and thrive. An SME could utilise differentiation as a strategy. Differentiation is offering a product or 
service that is perceived as unique, has innovative attributes and adds value (Douglas, Douglas \& Davies 2010:374). The existence of uniqueness could allow an SME to offer the product or service at a premium. Possible strategies for differentiation include warranties, unique features, brand image, and service quality. Differentiation is especially suitable to small businesses; because of their nature, size and flexibility they can adopt change and implement new strategies (Taneja et al. 2016:44). The ability for SMEs to match growing customer expectations regarding products and services is largely based on the SMEs' ability to innovate and deliver products and services that the customers perceive to be of high quality. Due to the unique characteristics of the service industry, specific requirements are essential such as leadership commitment, employee training, internal communication regarding quality and supportive organisational culture (Lam, Lee, Ooi \& Phusavat 2012:284).

A notable differentiation strategy is to use service quality, which is a measure of the value provided based on the difference between customers' perceptions and expectations of the service offering (Badruldin, Mohamed, Sharifuddin, Rezai, Abdullah, Latif \& Mohayidin 2012:61; Strombeck \& Shu 2013:161-162). Customers' perceptions of the service provided are based on service dimensions of reliability, empathy, responsiveness, tangibles and assurances (Chenet, Dagger \& O'Sullivan 2010:337). Small businesses may consider service quality standards as an important survival and growth mechanism (Owusu-Frimpong \& Nwankwo 2012:684; Tseng \& Wu 2014:77), particularly as service quality is a useful measure of organisational performance (Kasul \& Motwani in Anuar \& Yusuff 2011:328). A measure of high service quality is required to ensure that it is offered. The SERVQUAL model has been identified as an excellent management and measurement model of the customer service offering. The SERVQUAL model identifies where the gaps are in the service offering and indicates service performance (Chitty, Hughes \& D'Allesandro 2012:246) thus showing where corrective measures can be implemented. Evaluating service quality in SMEs is necessary considering that SMEs produce more jobs than larger companies and are an essential driver for growth and innovation (Anuar \& Yusuff 2011:324). Considering the difference in resources and capabilities of small businesses compared to that of larger businesses, the purpose of this paper is to determine whether small businesses can measure their service offering in the same fashion as that of large businesses. A more in-depth discussion on service quality and its components are found in the following section.

\section{Literature review}

Service is characterised as delivering intangible goods, which are varied according to the individual/s delivering the service and the "goods" being delivered that are consumed simultaneously. While quality is regarded as the perception of value (Lam et al. 2012:282). Service quality is the discrepancy between the customers' perceptions of a service offered by a business and the customers' expectations of companies offering that particular service (Badruldin et al. 2012:61). Customer perceptions can be considered as beliefs about service delivery that serve as a reference point against which consumers will make judgements (Wilson, Zeithmal, Bitner \& Gremler 2008:55). Customers will consider perceptions as their reality as it is referred to as the overall evaluation of the service provided and a subjective response to it (Suki, Lian \& Suki 2011:43). Perception is comparing expectations with performance (Parasuraman in Suki et al. 2011:40). Thus, perceptions together with expectations can be likened to a positive indication of quality if the perception of the services rendered is higher than the expectation of the services. The reverse is an indication of poor quality if the expectations of the service are higher than the perceptions of the service. Perceived service quality from the company's perspective can also be measured in an effort to understand how companies view their own service quality. SME owners should identify customers' needs and wants, then a service should be created that will satisfy the customer in such a way that it is not necessary for them to consider competing services (Machado \& Diggines 2012:120). Perceived quality is the service experienced while using the service, which is an important factor of customers' satisfaction and in turn affects their intention to utilise a service (Zeithaml in Nekoei-Moghadam \& Amiresmaili 2011:58).

By measuring the service quality perceptions of the small business, small business providers are able to detect which system processes are in need of adjustments (Suki et al. 2011:44). SERVQUAL has been identified as a powerful diagnostic authority for the measurement of service quality, however 
despite the widespread usage, there has been numerous criticisms regarding its theoretical and procedural bases (Owusu-Frimpong \& Nwankwo 2012:685). The SERVQUAL model was originally created with the following ten dimensions: reliability, responsiveness, competence, access, courtesy, communication, credibility, security, understanding/knowing the customer and tangibles (Buttle 2009:246). However, the SERVQUAL model was later refined to include only five core dimensions (Chitty et al. 2012:246) which are:

- reliability (Performing the service dependably and accurately);

- assurance (Employees' conveyance of trust, confidence, product/service knowledge and courtesy towards customers);

- tangibles (Physical facilities, equipment, personnel attire and communication medium's appearances);

- empathy (Caring and individualised attention for the customers) and

- Responsiveness (Prompt assistance for customers).

The importance of each dimension can be calculated and the difference between perceptions and expectations indicates customer satisfaction. The differences between expectations and perceptions are known as gaps (Buttle 2009:203) that provide insight as to where corrections can be made. If poor service is experienced then it is an indication of a gap, which reflects as a negative number based on the following equation (Hernon \& Altman 2010:88): SERVQUAL Gap score = perception score - expectation score. The SERVQUAL model is a necessary measurement tool to take continuously corrective measures to the service quality provided to remain competitive with service quality as the differentiating strategy. It is necessary to remaining competitive, as the environment in which small and large businesses alike operate, requires for either type of business to have a differentiating factor for them to stand out from the other businesses in a competitive environment. Despite the mainstream use of SERVQUAL to measure service quality and perform corrective measures where necessary, to remain competitive with service quality as the differentiation strategy, the initial SERVQUAL model would have perhaps been more suited to small businesses. The initial model would have been suited particularly considering that small businesses do not have as many human resources, finances, information technology hardware and software that large businesses possess (Buttle 2009:246; Dessi et al. 2014:669). In addition, the SERVQUAL model is not appropriate for all service offerings, as the dimensions do not relate to all service activities. Handrinos, Folinas and Rotsios (2015) give an example of a research study that adapted SERVQUAL to suit the service offering by either adding more dimensions or replacing the existing dimensions. Parasuraman (in Handrinos et al. 2015) indicated that at SERVQUAL's inception, dimensions could be added or deleted to suit the service industry; the existing dimensions serve as a starting point to measure service quality.

Therefore, based on the service quality offering in small businesses, SERVQUAL may have to be adapted to suit the unique needs for each small business industry. Unique needs of a small business could include increased competence considering lack of financial resources to hire too many employees; access to information technology; physical location may be more difficult for small businesses to obtain; communication, as small businesses may not have the HR capacity to respond to an overflow of emails or telephone calls; or credibility as small businesses are often unknown compared to the reputation of a larger business (Sandhu, Hassain \& Matlay 2012:728). Small businesses outsource many tasks due to lack of expertise or due to cost reduction, which means some of the services are not even provided by the small business itself (Edvardsson \& Teitsdóttir 2015:32). Based on the nature of the small business sector and the particular challenges and opportunities, service quality should be a differentiating strategy, which could provide a competitive advantage for SMEs in South Africa. Differentiation by means of service delivery implies that SMEs recognise the necessity of service delivery measurement and related corrective actions. This gives rise to the question: Can SMEs use SERVQUAL to measure service quality given the constraints relating to human resources, finances, information technology hardware and software that large businesses possess?

\section{Aim}

The SERVQUAL model with its five dimensions represents both the expectations and perceptions of service quality as seen by management of small businesses. The main aim of the study is to establish 
whether the SERVQUAL model is an inclusive indicator of SMEs' service quality during an economic downgrade.

\section{Methodology}

A sample of small business owners were asked to complete a quantitative questionnaire designed to measure the different dimensions of service quality as defined by the SERVQUAL model. The measured perspectives are the opinions of the SME owners regarding the importance of certain business aspects that influence service quality (their expectations) as well as their perceptions regarding how successful their businesses are in adhering to these aspects. Expectations and perceptions of service quality was measured on the dimensions of reliability, empathy, responsiveness, tangibles and assurances by means of a 5-point Likert scale with 22 items each (1=Strongly disagree; $2=$ Disagree; $3=$ Neutral; $4=$ Agree; $5=$ Strongly agree) as indicated in the SERVQUAL model.

Data was collected by means of electronically distributed self-administered questionnaires to a sample of SME owners operating in Gauteng and KwaZulu-Natal who registered their small businesses on an official state institution database that provides financial, administrative and marketing services to SMEs (with permission of the state institution and the SME owners). A non-probability, convenience sampling methodology was utilised to enable the researcher to collect data quickly and easily. Sufficient number of questionnaires was distributed to achieve a confidence level of 95 percent and an error margin of 5 percent at 50 percent response distribution. A total of 123 usable responses were received which is an error margin of 8.14 percent. The online Raosoft sample calculator was used to calculate the sample.

Confirmatory factor analysis in conjunction with structural equation modelling was employed for the analysis of the Likert scales. The results are discussed in the subsequent section.

\section{Research findings}

The respondents were asked to indicate the extent to which they agree that all businesses should adhere to a list of aspects (SERVQUAL) pertaining to service quality (expectations) by selecting a score from a five-point Likert scale ( $1=$ Strongly disagree; $2=$ Disagree; $3=$ Neutral; $4=$ Agree; $5=$ Strongly agree). The same was done regarding the perceptions of the respondents of the extent to which the expectations are realised (perceptions) in their own businesses. The psychometric properties of the SERVQUAL service-quality instrument are presented in terms of its reliability and validity in the sections to follow. These results give an indication of the extent to which the SERVQUAL instrument works as intended for this kind of data in a South African context.

The combined contribution of these provinces to the national GDP is 50 per cent (Gauteng 33.9 per cent; KwaZulu-Natal 16.1 per cent) and can therefore be regarded as representative of SMEs in South Africa (Gauteng Online, 2015). The respondent group consisted of owners (45.45 per cent), managers (18.18 percent) and owner managers (36.36 percent). The majority (58.46 percent) of these businesses had been operating for less than five years whereas a small portion (4.46 percent) existed for more than 25 years. The majority (58.62 percent) of respondents was female and more than half ( 56.9 percent) was older than 40 years. Almost two thirds (62.12 percent) of the respondents had a post-school qualification ranging from certificates to post-graduate degrees. An overview of the main results is provided in the next section.

\subsection{Reliability of the Servqual instrument}

The Cronbach's alpha coefficients, a measure of internal consistency, computed for the SERVQUAL in total, as well as for the various dimensions of service quality it measured. These coefficients are presented in Table 1. 


\begin{tabular}{|c|c|c|}
\hline & \multicolumn{2}{|c|}{ Current study } \\
\hline & Expectations & Perceptions \\
\hline & $\begin{array}{c}\text { Cronbach's Alpha } \\
\text { (Number of items) } \\
\text { [a increases if item deleted] }\end{array}$ & $\begin{array}{c}\text { Cronbach's Alpha } \\
\text { (Number of items) } \\
{[a \text { increases if item deleted] }}\end{array}$ \\
\hline All items & $0.932(22)$ & $0.946(22)$ \\
\hline Tangibles & $0.809(4)$ & $0.806(4)$ [P_TAN_3] \\
\hline Reliability & $0.817(5)$ [E_REL_9] & $0.867(5)$ \\
\hline Responsiveness & 0.811(4) [E_RES_13] & 0.783(4) [(P_RES_13] \\
\hline Assurance & $0.897(4)$ & $0.881(4)$ \\
\hline Empathy & 0.791(5) [E_EMP_19] & $0.938(5)$ \\
\hline
\end{tabular}

Table 1: Cronbach Alpha coefficients of the SERVQUAL instrument

Source: Author's own research results

Overall, a Cronbach's alpha of 0.932 for expectations and 0.946 for perceptions indicate that the reliability of the scale overall is very high in both sets of data. Although lower, the reliabilities found for the individual dimensions also demonstrate high internal consistency.

\subsection{Validity of the SERVQUAL instrument}

To assess the validity of the SERVQUAL instrument, confirmatory factor analysis (CFA) was employed, postulating a model with the 22 items of the SERVQUAL and their corresponding latent constructs. To assess this dimensionality of the SERVQUAL instrument (whether the five factors can provide a plausible explanation of the co-variances among the measured question items), IBM SPSS Amos 22 was used and the CFA models that were fitted to the expectations and perceptions data are shown in Figure 1 and Figure 2 respectively.

\subsection{Expectations}

Each construct with the associated items was assessed individually and E_TAN_4 (Materials like pamphlets or statements linked with the service, will be visually appealing); E_REL_9 (Insist on error-free records); ERES_13 (Employees are never too busy to respond to customers' requests); and E_EMP_19 (Operating hours will be convenient to all customers) were found not to contribute to the solution with squared multiple correlations below 0.3 and was therefore left out of the initial model.

The initial model also had no co-variances between error terms, and no cross-loading of items to other latent variables. However, an inspection of the modification indices indicated that path coefficients could be included between the latent variable "tangibles" and E_REL_5 as well as E_REL_7 between "reliability" and E_RES_12, and between "assurance" and E_RES_10 and E_EMP_18. Theoretically, the addition of these path coefficients could be justified from the item content. Thus, based on the responses from the current sample of SME owners, it seems as though in a South African context, cross-loadings should be allowed when applying CFA to the SERVQUAL instrument when it is used to measure importance (expectations) of service aspects. The addition of these parameters to the model improved the fit. Due to indication from the modification indices that the model fit will improve by allowing E_TAN_3 to cross-load on three of the other latent constructs, it was decided to drop this item from the model, which resulted in a substantial improvement in fit. Modification indices that indicated large possible improvements in model fit statistics were between errors terms E_REL_5 and E_EMP_18, E_RES_10 and E_RES_11, E_RES_12 and E_EMP_18 as well as between E_RES_11 and E_ASS_16. From the item content, the inclusion of these co-variance parameters between the error terms of the items could be theoretically justified. For example, there could be some overlap in interpretation of "Employees will tell customers exactly when services will be performed" (responsiveness) and "The employees will understand the specific needs of their customers" (empathy). Subsequent addition of these error co-variance parameters to the model improved the fit. 


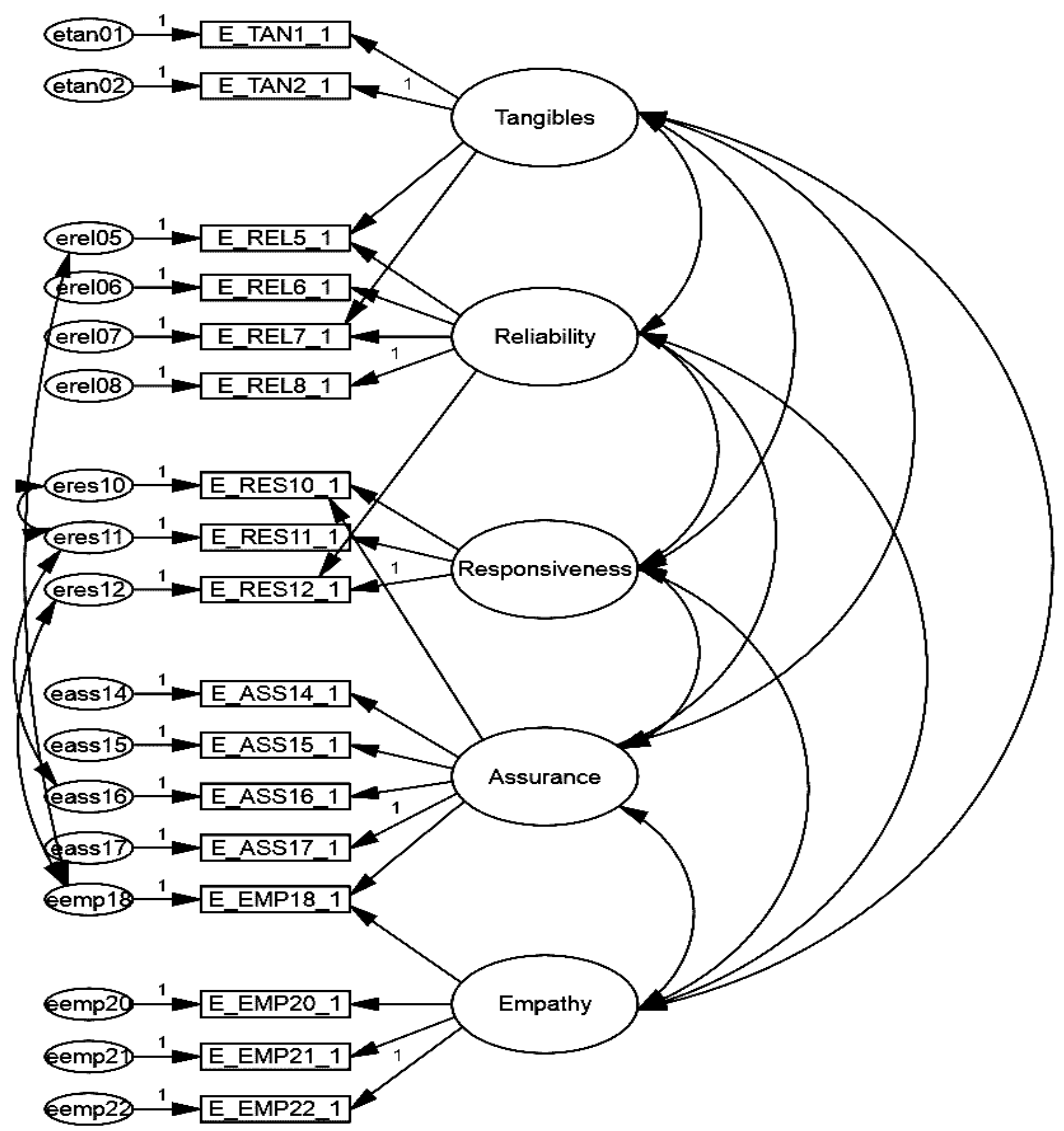

Figure 1: Confirmatory factor analysis of the SERVQUAL instrument Source: Author's own research results

The parameter estimates of the regression coefficients are provided in Table 2 and the estimated co-variances for the model are provided in Table 3. Table 4 provides a summary of the most important fit measures for the SERVQUAL model in Figure 1.

All the coefficients are positive and significant at the 5 percent level of significance, which is an indication that high levels on the latent variables will be associated with higher levels on the items. Although the regression weight E_RES_10 $\leftarrow$ Responsiveness is marginally non-significant, it was decided to retain the regression path in the model so as not to have to eliminate E_RES_10 from the model. For the model to be identified and to set the scale for the latent constructs, one of the regression paths is constrained to be equal to one. In the structural equation modelling (SEM) literature, this method of constraining one item path for each latent construct to be equal to one is generally recommended (Steenkamp and Baumgartner, 1998).

\begin{tabular}{|c|c|c|c|c|c|}
\hline & & Estimate & S.E. & C.R. & $P$ \\
\hline E_EMP22_1 < & $\begin{array}{ll}<--- & \text { Empathy }\end{array}$ & 1.000 & & & \\
\hline E_EMP21_1 < & Empathy & 1.143 & .127 & 9.020 & $* * *$ \\
\hline E_EMP20_1 < & $<---\quad$ Empathy & 1.274 & .145 & 8.808 & $* * *$ \\
\hline E_ASS17_1 < & <--- Assurance & 1.000 & & & \\
\hline E_ASS16_1 $<$ & <--- Assurance & 1.040 & .084 & 12.336 & $* * *$ \\
\hline E_ASS15_1 < & <--- Assurance & .845 & .088 & 9.607 & $* * *$ \\
\hline E_ASS14_1 & <--- Assurance & .864 & .087 & 9.988 & *** \\
\hline E_RES12_1 & $<--$ Responsiveness & 1.000 & & & \\
\hline E_RES11_1 < & $<--$ Responsiveness & .584 & .083 & 7.056 & $* * *$ \\
\hline E_RES10_1 < & <--- Responsiveness & .218 & .116 & 1.880 & .060 \\
\hline
\end{tabular}




\begin{tabular}{|c|c|c|c|c|c|}
\hline & & Estimate & S.E. & C.R. & $\mathrm{P}$ \\
\hline E_REL8_1 & <--- Reliability & 1.000 & & & \\
\hline E_REL7_1 & <--- Reliability & .920 & .113 & 8.166 & $* * *$ \\
\hline E_REL6_1 & <--- Reliability & 1.375 & .149 & 9.244 & $* * *$ \\
\hline E_REL5_1 & <--- Reliability & .473 & .100 & 4.723 & $* * *$ \\
\hline E_TAN2_1 & $<---\quad$ Tangibles & 1.000 & & & \\
\hline E_TAN1_1 & $<---\quad$ Tangibles & 1.093 & .153 & 7.140 & $* * *$ \\
\hline E_EMP18_1 & <--- Assurance & .708 & .094 & 7.551 & $* * *$ \\
\hline E_REL5_1 & <--- Tangibles & .227 & .065 & 3.487 & $* * *$ \\
\hline E_RES12_1 & <--- Reliability & -.930 & .251 & -3.708 & $* * *$ \\
\hline E_EMP18_1 & <--- Empathy & .191 & .088 & 2.165 & .030 \\
\hline E_REL7_1 & $<---\quad$ Tangibles & .149 & .056 & 2.637 & .008 \\
\hline E_RES10_1 & <--- Assurance & .580 & .174 & 3.331 & $* * *$ \\
\hline
\end{tabular}

Table 2: Maximum likelihood estimates of regression weights for model in Figure 1 Source: Author's own research results

All the co-variances are positive and significant (Table 3).

\begin{tabular}{|c|c|c|c|c|c|}
\hline & & Estimate & S.E. & C.R. & $\mathrm{P}$ \\
\hline Empathy & <--> Assurance & .230 & .056 & 4.081 & *** \\
\hline Assurance & <--> Responsiveness & .477 & .097 & 4.920 & $* * *$ \\
\hline Empathy & <--> Responsiveness & .379 & .091 & 4.149 & $* * *$ \\
\hline Responsiveness & <--> Reliability & .391 & .100 & 3.906 & $* * *$ \\
\hline Assurance & <--> Reliability & 139 & .043 & 3.226 & .001 \\
\hline Empathy & <--> Reliability & .145 & .044 & 3.292 & $* * *$ \\
\hline Reliability & <--> Tangibles & 137 & .053 & 2.569 & .010 \\
\hline Responsiveness & Tangibles & .278 & .100 & 2.791 & .005 \\
\hline Assurance & Tangibles & .183 & .064 & 2.864 & .004 \\
\hline Empathy & <--> Tangibles & .276 & .071 & 3.897 & $* * *$ \\
\hline eemp18 & <--> eres12 & .041 & .017 & 2.385 & .017 \\
\hline eemp18 & <--> erel05 & .042 & .017 & 2.505 & .012 \\
\hline eres11 & eres10 & .096 & .026 & 3.770 & $* * *$ \\
\hline eass16 & eres11 & .038 & .013 & 2.996 & .003 \\
\hline
\end{tabular}

Table 3: Estimated co-variances for model in Figure 1

Source: Author's own research results

\subsubsection{Measures of fit}

The Chi-square statistic is not always suitable in the case of large samples; however, in the case of this research it can be used as a measure of the fit of the model. Since the Chi-square tests the null hypothesis that the data fits the model well, the idea is to get a non-significant result so that the null hypothesis cannot be rejected. For this expectation data the non-significant result $(\chi 2(100)=118.381, p=$ 0.101 ) indicates that the data fits the model in Figure 1 well. A number of the most important fit measures with their evaluation criteria are listed in Table 4, showing that some of these fit indices confirm the Chisquare result. The acceptable levels of fit are indicated in parentheses for each of the listed indices.

CMIN ( $p>0.05 ; \mathrm{CMIN} / \mathrm{DF} \leq 2)$

\begin{tabular}{|l|rrrrr|}
\hline Model & NPAR & CMIN & DF & P & CMIN/DF \\
\hline Default model & 53 & 118.381 & 100 & .101 & 1.184 \\
Saturated model & 153 & .000 & 0 & & \\
Independence model & 17 & 1266.691 & 136 & .000 & 9.314 \\
\hline
\end{tabular}


RMR, GFI (RMR close to 0; GFI close to 1)

\begin{tabular}{|l|rrrr|}
\hline Model & RMR & GFI & AGFI & PGFI \\
\hline Default model & .026 & .883 & .821 & .577 \\
Saturated model & .000 & 1.000 & & \\
Independence model & .243 & .227 & .130 & .202 \\
\hline
\end{tabular}

Baseline Comparisons (0.9 and above)

\begin{tabular}{|c|c|c|c|c|c|}
\hline Model & $\begin{array}{r}\text { NFI } \\
\text { Delta1 }\end{array}$ & $\begin{array}{r}\text { RFI } \\
\text { rho1 }\end{array}$ & $\begin{array}{r}\text { IFI } \\
\text { Delta2 }\end{array}$ & $\begin{array}{r}\text { TLI } \\
\text { rho2 }\end{array}$ & CFI \\
\hline Default model & .907 & .873 & .984 & .978 & .984 \\
\hline Saturated model & 1.000 & & 1.000 & & 1.000 \\
\hline Independence model & .000 & .000 & .000 & .000 & .000 \\
\hline \multicolumn{6}{|c|}{ RMSEA (.05 and below) } \\
\hline Model & RMSEA & LO 90 & & HI 90 & PCLOSE \\
\hline Default model & .044 & .000 & & .073 & .596 \\
\hline Independence model & .299 & .284 & & .314 & .000 \\
\hline
\end{tabular}

Table 4: Summary of important fit measures for the SERVQUAL model in Figure 1

Source: Author's own research results

Thus, it seems that the SERVQUAL instrument, when used to measure the expectations (importance) of service quality aspects according to business owners in South Africa, functions largely as intended with only four of the items that are not quite interpreted as intended.

\subsection{Perceptions}

Each construct with the associated items was assessed individually and P_TAN_3 (Employees will be neat in their appearance) and P_RES_13 (Employees are never too busy to respond to customers' requests) were found not to contribute to the solution with squared multiple correlations below 0.3; it was therefore left out of the initial model. The initial model also had no co-variances between error terms, and no cross-loading of items to other latent variables. However, the modification indices indicated that a path coefficient could be included between the latent variable "assurance" and P_EMP_20. Theoretically, the addition of this path coefficient could be justified from the item content. Thus, based on the responses from the current sample of SME owners, it seems as though in a South African context, this cross-loading should be allowed when applying CFA to the SERVQUAL instrument when it is used to measure business owners' perceptions of the extent to which service aspects are realised in their businesses. The addition of this parameter to the model improved the fit. Due to indication from the modification indices that the model fit will improve by allowing P_TAN_4 to cross-load on all of the other latent constructs, it was decided to drop this item from the model, which resulted in a substantial improvement in fit. Modification indices that indicated large possible improvements in model fit statistics were between errors terms P_TAN_01 and P_RES_12, P_REL_5 and P_RES_10, P_REL_6 and P_RES_12, P_REL_8 and P_EMP_22, P_RES_11 and P_EMP_18, P_RES_12 and P_EMP_19 as well as between P_EMP_20 and P_EMP_21. From the item content, the inclusion of these co-variance parameters between the error terms of the items could be theoretically justified. For example, there could be some overlap in interpretation of "Reliable" (reliability) and "Employees will tell customers exactly when services will be performed" (responsiveness). Subsequently addition of these error co-variance parameters to the model improved the fit. 


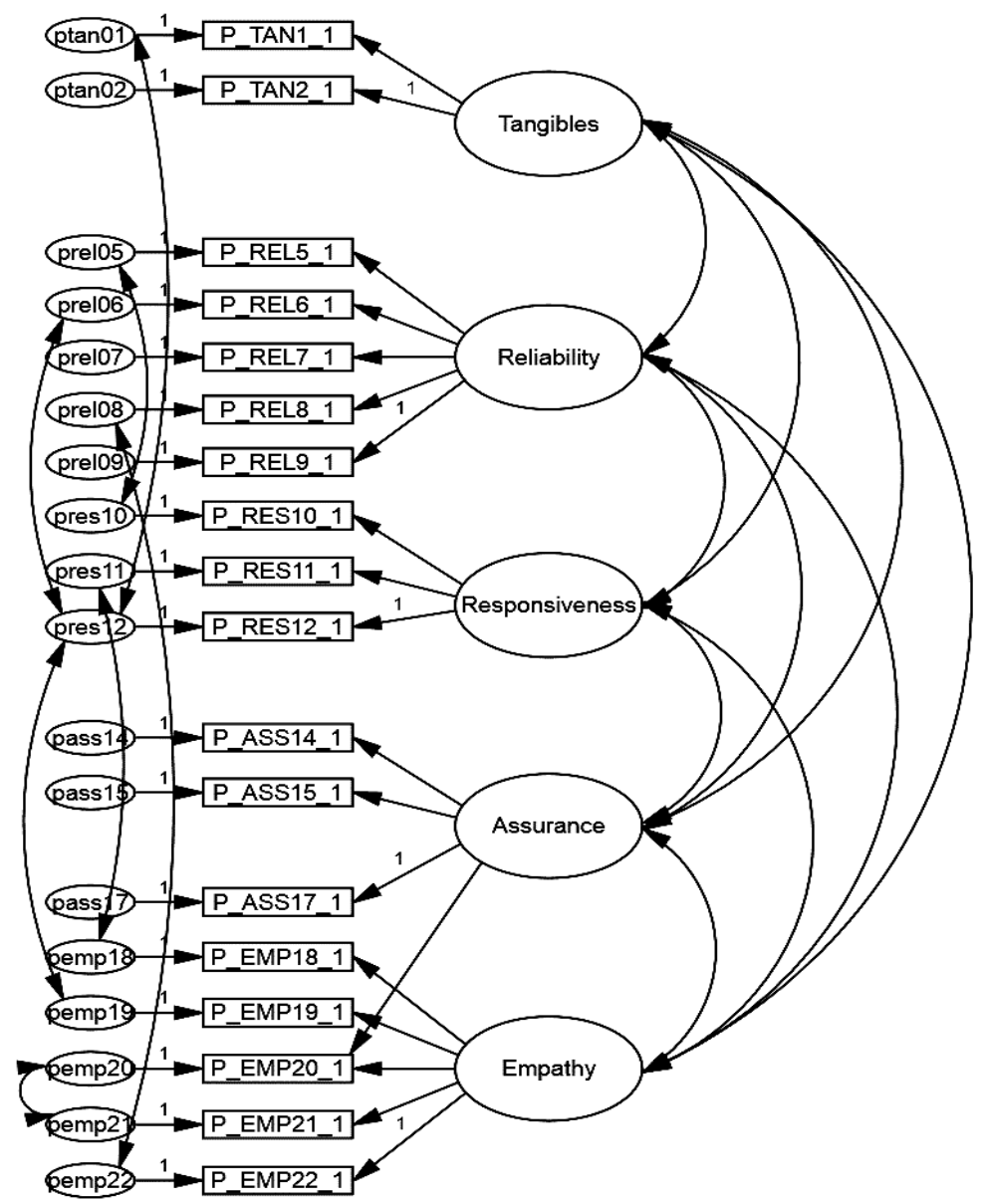

Figure 2: Confirmatory factor analysis of the SERVQUAL instrument Source: Author's own research results

The parameter estimates of the regression coefficients are provided in Table 5 and the estimated co-variances for the model are provided in Table 6 . All the coefficients are positive and significant at the 5 percent level of significance.

\begin{tabular}{|c|c|c|c|c|c|}
\hline & & Estimate & S.E. & C.R. & $\mathrm{P}$ \\
\hline P_EMP22_1 <- & <--- Empathy & 1.000 & & & \\
\hline P_EMP21_1 <- & <--- Empathy & .952 & .068 & 14.038 & $* * *$ \\
\hline P_EMP20_1 <- & <--- Empathy & .500 & .189 & 2.646 & .008 \\
\hline P_EMP19_1 <- & <--- Empathy & .926 & .112 & 8.242 & $* * *$ \\
\hline P_EMP18_1 <- & <--- Empathy & 1.027 & .073 & 14.006 & $* * *$ \\
\hline P_ASS17_1 <- & $<--$ Assurance & 1.000 & & & \\
\hline P_ASS15_1 & Assurance & .964 & .124 & 7.776 & $* * *$ \\
\hline P_ASS14_1 & <--- Assurance & 1.222 & 159 & 7.697 & $* * *$ \\
\hline P_RES12_1 & <--- Responsiveness & 1.000 & & & \\
\hline P_RES11_1 & <--- Responsiveness & 1.092 & .134 & 8.161 & *** \\
\hline P_RES10_1 & <--- Responsiveness & 1.237 & .146 & 8.446 & $* * *$ \\
\hline P_REL9_1 & <--- Reliability & 1.000 & & & \\
\hline P_REL8_1 & <--- Reliability & .780 & .106 & 7.364 & $* * *$ \\
\hline P_REL7_1 & $<--$ Reliability & .918 & .119 & 7.690 & $* * *$ \\
\hline P_REL6_1 & <--- Reliability & .905 & .136 & 6.640 & $* * *$ \\
\hline P_REL5_1 & <--- Reliability & .978 & .133 & 7.363 & *** \\
\hline P_TAN2_1 & <--- Tangibles & 1.000 & & & \\
\hline
\end{tabular}




\begin{tabular}{|ll|rrrr|}
\hline & & Estimate & S.E. & C.R. & P \\
\hline P_TAN1_1 <--- & Tangibles & .945 & .117 & 8.071 & $* * *$ \\
P_EMP20_1 <--- & Assurance & .646 & .201 & 3.214 & .001 \\
\hline
\end{tabular}

Table 5: Maximum likelihood estimates of regression weights for model in Figure 1 Source: Author's own research results

All the co-variances are positive and significant (Table 6).

\begin{tabular}{|c|c|c|c|c|c|c|}
\hline & & & Estimate & S.E. & C.R. & $\mathrm{P}$ \\
\hline Empathy & $<-->$ & Assurance & .207 & .041 & 5.078 & $* * *$ \\
\hline Assurance & $<-->$ & Responsiveness & .205 & .044 & 4.686 & $* * *$ \\
\hline Empathy & $<-->$ & Responsiveness & .202 & .040 & 5.055 & *** \\
\hline Responsiveness & $<-->$ & Reliability & .254 & .053 & 4.775 & $* * *$ \\
\hline Assurance & $<-->$ & Reliability & .244 & .052 & 4.687 & $* * *$ \\
\hline Empathy & $<-->$ & Reliability & .227 & .046 & 4.940 & $* * *$ \\
\hline Reliability & $<-->$ & Tangibles & .255 & .070 & 3.633 & $* * *$ \\
\hline Responsiveness & $<-->$ & Tangibles & .236 & .062 & 3.823 & $* * *$ \\
\hline Assurance & $<-->$ & Tangibles & .131 & .056 & 2.315 & .021 \\
\hline Empathy & $<-->$ & Tangibles & .143 & .054 & 2.647 & .008 \\
\hline pres12 & $<-->$ & prel06 & .100 & .025 & 3.959 & $* * *$ \\
\hline pemp21 & $<-->$ & pemp20 & .029 & .012 & 2.495 & .013 \\
\hline pres12 & $<-->$ & $\operatorname{ptan} 01$ & -.076 & .024 & -3.172 & .002 \\
\hline pemp18 & $<-->$ & pres11 & .041 & .013 & 3.147 & .002 \\
\hline pemp19 & $<-->$ & pres12 & .088 & .023 & 3.782 & $* * *$ \\
\hline pres10 & $<-->$ & prel05 & -.077 & .021 & -3.694 & $* * *$ \\
\hline pemp22 & $<-->$ & prel08 & -.045 & .011 & -4.099 & $* * *$ \\
\hline
\end{tabular}

Table 6: Estimated co-variances for model in Figure 1

Source: Author's own research results

Table 7 provides a summary of the most important fit measures for the SERVQUAL model in Figure 2.

\subsubsection{Measures of fit}

As for the expectation data, the non-significant Chi-square result for the perceptions data $(\chi 2(117)=$ $139.510, p=0.076)$ indicates that the data fits the model in Figure 2 well. Other fit statistics are listed in Table 7.

\begin{tabular}{|l|rrrrr|}
\multicolumn{1}{c|}{ CMIN $(p>0.05 ;$ CMIN/DF $\leq 2)$} \\
Model & NPAR & CMIN & DF & P & CMIN/DF \\
\hline Default model & 54 & 139.510 & 117 & .076 & 1.192 \\
Saturated model & 171 & .000 & 0 & & \\
Independence model & 18 & 1456.902 & 153 & .000 & 9.522 \\
\hline
\end{tabular}

\begin{tabular}{|l|rrrr|}
\hline \multicolumn{2}{|c|}{ RMR, GFI (RMR close to 0; GFI close to 1) } \\
\hline Model & RMR & GFI & AGFI & PGFI \\
\hline Default model & .024 & .863 & .800 & .590 \\
Saturated model & .000 & 1.000 & & \\
Independence model & .229 & .169 & .072 & .152 \\
\hline
\end{tabular}

\begin{tabular}{|l|rrrrr|}
\hline \multicolumn{7}{|c|}{ Baseline Comparisons (0.9 and above) } \\
Model & $\begin{array}{r}\text { NFI } \\
\text { Delta1 }\end{array}$ & $\begin{array}{r}\text { RFI } \\
\text { rho1 }\end{array}$ & $\begin{array}{r}\text { IFI } \\
\text { Delta2 }\end{array}$ & $\begin{array}{r}\text { TLI } \\
\text { rho2 }\end{array}$ & CFI \\
\hline Default model & .904 & .875 & .983 & .977 & .983 \\
Saturated model & 1.000 & & 1.000 & & 1.000 \\
Independence model & .000 & .000 & .000 & .000 & .000 \\
\hline
\end{tabular}

\begin{tabular}{|l|rrrr|}
\hline Model & \multicolumn{4}{c|}{ RMSEA (.05 and below) } \\
\hline Default model & RMSEA & LO 90 & HI 90 & PCLOSE \\
\hline
\end{tabular}

www.jbrmr.com A Journal of the Academy of Business and Retail Management (ABRM) 103 


\begin{tabular}{|l|rrrr|}
\hline Model & RMSEA & LO 90 & HI 90 & PCLOSE \\
\hline Independence model & .303 & .289 & .317 & .000 \\
\hline
\end{tabular}

Table 7: Summary of important fit measures for the SERVQUAL model in Figure 2

Source: Author's own research results

Thus, it seems that the SERVQUAL instrument, when used to measure the perceptions of service quality aspects according to business owners in South Africa, functions largely as intended. However, four of the items that are not quite interpreted as intended.

\section{Conclusion}

To stimulate economic growth, job creation within the small business sector is desperately needed (Affirmative portfolios 2016; Statistics SA 2015), especially since small businesses are relatively more labour intensive (relating to the unskilled to semi-skilled labour). In view of the low-skilled labour (elementary and domestic workers occupations) employment numbers compared to the semi-skilled labour (clerks, sales and services, machine workers, skilled agriculture) and skilled labour (managers, professionals and technicians), there is an overflow of unemployed unskilled labour in South Africa. Service quality is a differentiating strategy that promotes economic growth objectives and profitability (Owusu-Frimpong and Nwankwo 2012:694), which is promoted to small businesses to utilise. The SERVQUAL model is an instrument that can be used to measure and manage service quality. This model measures the gap between customer expectations and experience on five dimensions comprising reliability, responsiveness, assurance, empathy and tangibility. Expectations have an overall Cronbach's alpha of 0.932 while Perceptions have an overall Cronbach's alpha of 0.946 - which are both very high reliability of the scale.

Thus, it seems that the SERVQUAL instrument, when used to measure the perceptions of service quality aspects according to business owners in South Africa, functions largely as intended. However, four of the items that are not quite interpreted as intended. For this expectation data the non-significant result $\left(\chi^{2}(100)=118.381, p=0.101\right)$ indicates that the data fits the model. As for the expectation data, the non-significant Chi-square result for the perceptions data $\left(\chi^{2}(117)=139.510, p=0.076\right)$ indicates that the data fits the model. For expectations the $p$-value $=0.101$, while for perceptions the $p$-value $=0.076$. There is no evidence that the model does not fit the data and it is deemed acceptable at a confidence level of 95 per cent or alpha at 0.05 with the p-value of expectations and perceptions, which are at 0.101 and 0.076 respectively. However, small businesses have to take what they can from the SERVQUAL model, in realising that what is suitable to large businesses does not automatically become suitable for small businesses. Large businesses have the resources to measure service quality with the SERVQUAL model, because of the access to human resources, finances and technical equipment. A small business will have either to employ someone or outsource the task to conduct the research by adjusting the statements of the SERVQUAL to their business offering. The employee will have to conduct the actual research, followed by the data collection and analyses. For analysis to occur, the necessary hardware and software need to be in place.

Furthermore, an employee would need to be able to interpret the results which is rather complex when specialised knowledge is required to do so. This study revealed that the factor structure of the service quality dimensions as determined by the SERVQUAL model, for both the data representing the expectations of service quality as well as the data representing the perceptions of actual service quality as seen by management, is largely supported by data obtained from South African SMEs. The SERVQUAL model is not ideal for small businesses when the entire model cannot be interpreted as intended, considering that only four items are not quite interpreted as intended. However, the SERVQUAL model does not measure service quality in its entirety, as there are aspects that differ between large and small businesses that are not addressed in the SERVQUAL model. The current study on the discrepancy in large and small business service quality is a contribution to the field of study in that it indicates possible adaptation of SERVQUAL to SME's. Small business owners will benefit from having a SERVQUAL model that differs from large businesses, in that they have a more specific and adapted model could be a better indicator of SME's service quality delivery. An adapted model of SERVQUAL may be more suitable for SMEs or a new model that will take in the unique characteristics of small businesses thus a model for 
small businesses should be researched to determine whether specific service quality aspects arise that differ from that of the SERVQUAL model.

\subsection{Research limitations and future research}

Limitations of the study include the restricted number of completed surveys in addition to the cities where the survey was distributed. The survey could have been distributed in other cities across the country in order to gain a wider South African view of service quality at small businesses.

Further research can be done on the matter of a service quality measurement model for SMEs. A study delving deeper into the service quality dimensions that would relate to small businesses in South Africa might be required. As South Africa has unique characteristics regarding its markets and where small businesses are located, such as in informal settlements or rural areas (beyond urban areas) a study could look at what service quality dimensions are unique to South African business owners and customers alike. Future studies can also look at overcoming the limitations presented in the current paper, regarding completed surveys and extending the reach to respondents in other geographical areas/cities in South Africa.

\section{References}

Affirmative portfolios (nd.). Shortage of skilled workers versus the overflow of unskilled labour in South Africa. [Online] Available at http://www.affirmativeportfolios.co.za/shortage-of-skilled-workers-versusthe-overflow-of-unskilled-labour-in-south-Africa/ [ accessed 12 Jan. 2017].

Anuar, A. and R. M, Yusuff (2011). Manufacturing best practices in Malaysian small and medium enterprises (SMEs). Benchmarking: An International Journal, [online] Volume 18 (3), pp. 324-341. Available at http://dx.doi.org/10.1108/14635771111137750 [Downloaded: 17 Jun. 2016].

Badruldin, B., Z. Mohamed, J. Sharifuddin, G. Rezai, A. M. Abdullah, I. Abd Latif, and G. Mohayidin (2012). Clients' perception towards JAKIM service quality in Halal certification. Journal of Islamic Marketing, [online] Volume 3 (1), pp.59-71. Available at:

http:/ /dx.doi.org/10.1108/17590831211206590 [accessed 4 Apr. 2016].

Buttle, F. (2009). Customer relationship management: concepts and technologies. Oxford, UK: ButterworthHeinemann.

Chenet, P., T. S. Dagger, and D. O'Sullivan (2010). Service quality, trust, commitment and service differentiation in business relationships. Journal of Services Marketing, [online] Volume 24 (5), pp. 336-346. Available at http:/ /dx.doi.org/10.1108/08876041011060440 [accessed 20 Jun.2016].

Chitty, W., A. Hughesand S. D'Allessandro (2012). Services Marketing, Victoria, AU: Oxford.

Dessi, C., W. Ng, M. Floris, and S. Cabras (2014). How small family-owned businesses may compete with retail superstores. Journal of Small Business and Enterprise Development, [online] Volume 21 (4), pp.668-689. Available at http://dx.doi.org/10.1108/JSBED-02-2014-0025 [accessed 20 Jun. 2016].

Douglas, A., J. Douglas, and. J. Davies (2010). Differentiation for competitive advantage in a small family business. Journal of Small Business and Enterprise Development, [online] Volume 17 (3), pp. 371-386. Available at http://dx.doi.org/10.1108/14626001011068680 [accessed 20 May 2016].

Edvardsson, I. R., and U. D. Teitsdóttir (2015). Outsourcing and financial crisis: evidence from Icelandic service SMEs. Employee Relations, [online] Volume 37 (1), pp. 33-47. Available at

http:/ / dx.doi.org/10.1108/ER-11-2013-0168 [accessed 05 Feb. 2016].

Festus, L., A. Kasongo, M. Moses and D. Yu (2016). The South African labour market, 1995-2015. Development Southern Africa, [online] Volume 33 (5), pp. 579-599. Available at

DOI: 10.1080/0376835X.2016.1203759 [accessed 23 Jan. 2017].

Gauteng Online, (2015). The Economy of Gauteng. Available at

http://www.gautengonline.gov.za/Business/Pages/The Economy of Gauteng. aspx (accessed 18 Apr. 2016).

Handrinos, M. C., Folinas, D. and K. Rotsios (2015). Using SERVQUAL model to evaluate the quality of services for a farm school store. Journal of Marketing and Consumer Behaviour in Emerging Markets, $1(1)$, pp. $62-74$.

Hernon, P. and E. Altman, (2010). Assessing service quality: satisfying the expectations of library customers, American Library Association. 
Lam, S., N. Lee, V., K. Ooi, and K. Phusavat (2012). A structural equation model of TQM, market orientation and service quality: evidence from a developing nation. Managing Service Quality, [online] Volume 22 (3), pp. 281-309. Available at http://dx.doi.org/10.1108/09604521211230996 [accessed 18 Jun. 2016].

Machado, R. and C. Diggines (2012). Customer Service. Cape Town: Juta.

Moody's Rating agency (2017). Moody's downgrades SA. Available at

http://www.fin24.com/Economy/full-statement-moodys-downgrades-sa-20170609 (accessed: 3 July 2017).

Nekoei-Moghadam, M. and M. Amiresmaili (2011). Hospital services quality assessment: Hospitals of Kerman University of Medical Sciences, as a tangible example of a developing country. International Journal of Health Care Quality Assurance, [online] Volume 24 (1), pp. 57-66. Available at

http:/ / dx.doi.org/10.1108/09526861111098247 [accessed 17 Jun. 2016].

Omarjee, L. (2017). Junk status hits entrepreneur confidence levels. Fin24. [Online] Available at

http://www.fin24.com/Entrepreneurs/junk-status-hits-entrepreneur-confidence-levels-20170510

Owusu-Frimpong, N. and S. Nwankwo (2012). Service quality orientation: an approach to diffusing mindfulness in SMEs. International Journal of Quality and Reliability Management, [online] Volume 29 (6), pp.681-698. Available at http://dx.doi.org/10.1108/02656711211245665 [accessed 17 Jun. 2016].

Sandhu, N., J. Hussain, and H. Matlay (2012). Entrepreneurship education and training needs of family business operating in the agricultural sector of India. Education and Training, 54(8/9), pp. 727-743.

South African Reserve Bank. (2016). Press Statement of Monetary Policy Committee: 19 May 2016. Available at https:/ / www.scribd.com/doc/313156346/Statement-of-the-Monetary-Policy-Committee [accessed 20 May 2016].

Statistics SA. (2015). Employment, unemployment, skills and economic growth: an exploration of household survey evidence on skills development and unemployment between 1994 and 2014. Available at

http:/ / www.statssa.gov.za/presentation/Stats\%20SA\%20presentation\%20on \%20skills\%20and \%20unem ployment_16\%20September.pdf [accessed 23 Jan. 2017].

Steenkamp, J-B.E.M. and H. Baumgartner (1998). Assessing measurement invariance in cross-national consumer research. Journal of Consumer Research, [online] Volume25 (1), pp. 78-107. Available at

http:/ / dx.doi.org/10.1086/209528 [accessed 20 May 2016].

Strombeck, S. and S. Shu (2013). Modelling contextually elicited service quality expectations. Managing Service Quality, [online] Volume 24 (2), pp. 160-183. Available at

http:/ / www.emeraldinsight.com/journals.htm?issn=0960-4529andvolume $=24$ andissue $=2$ andarticleid= 17104556andshow $=$ htmland [accessed 17 Jun. 2016].

Suki, N., J.C.C. Lian, and N. Mohd Suki (2011). Do patients' perceptions exceed their expectations in private healthcare settings? International Journal of Health Care Quality Assurance, [online] Volume 24 (1), pp. 42-56. Available at http://dx.doi.org/10.1108/09526861111098238 [accessed 20 May 2016].

Taneja, S., M. G. Pryor, and M. Hayek (2016). Leaping innovation barriers to small business longevity. Journal of Business Strategy, [online] Volume 37 (3), pp. 44-51. Available at

http://dx.doi.org/10.1108/JBS-12-2014-0145 [accessed 20 May 2016].

Tseng, S. and P. Wu (2014). The impact of customer knowledge and customer relationship management on service quality. International Journal of Quality and Service Sciences, [online] Volume 6 (1), pp. 7796. Available at http://dx.doi.org/10.1108/IJQSS-08-2012-0014 [accessed 04 Apr. 2016].

Wilson, A., V.A. Zeithaml,M.J. Bitner, and D.D. Gremler (2008). Services marketing: integrating customer focus across the firm. Berkshire, UK: McGraw-Hill.

Zhang, M., Y. Xie., and Z. He (2014). Service quality evaluation of car rental industry in China. International Journal of Quality and Reliability and Management, [online] Volume 31 (1), pp. 82-102. Available at http://dx.doi.org/10.1108/IJQRM-11-2012-0146 [accessed 04 Apr. 2016]. 